\title{
Sesquiterpene Cyclizations inside the Hexameric Resorcinarene Capsule: Total Synthesis of $\delta$-Selinene and Mechanistic Studies
}

\author{
Qi Zhang, ${ }^{[a]}$ and Konrad Tiefenbacher ${ }^{*[b]}$
}

\begin{abstract}
The synthesis of terpene natural products remains a challenging task due to the enormous structural diversity in this class of compounds. Synthetic catalysts are unable to reproduce the tail-tohead terpene cyclization of cyclase enzymes, which creates this diversity from just a few simple linear terpene substrates. Recently, supramolecular structures emerged as promising enzyme mimetics. In the present study, the hexameric resorcinarene capsule was utilized as an artificial cyclase to catalyze the cyclization of sesquiterpenes. With the cyclization reaction as the key step, the first total synthesis of the sesquiterpene natural product $\delta$-selinene was achieved. This represents the first total synthesis of a sesquiterpene natural product that is based on the cyclization of a linear terpene precursor inside a supramolecular catalyst. To elucidate the reaction mechanism, detailed kinetic studies and kinetic isotope measurements were performed. Surprisingly, the obtained kinetic data indicated that a rate-limiting encapsulation step is operational in the cyclization of sesquiterpenes.
\end{abstract}

\section{Introduction}

The synthesis of terpene natural products continues to be a worthwhile endeavour due to their biological functions, medicinal applications, and structural complexity. ${ }^{[1]}$ To more efficiently access these compounds, their biosyntheses ${ }^{[2]}$ serve as an important inspiration for chemists. In nature, farnesyl pyrophosphate (1, Scheme 1a) serves as the direct precursor for the whole variety of cyclic sesquiterpene natural products. Two classes of enzymes convert the acyclic precursors: type I and type II cyclases. The cyclization reaction catalyzed by the type II enzymes has already been successfully mimicked to some degree in solution and applied in synthesis. ${ }^{[3]}$ This type of cyclization reaction is initiated at the prenyl moiety of the substrate ("head" part, Scheme 1a), usually via protonation. The resulting positive charge then propagates to the "tail" part to form compounds featuring decalin-skeletons in the case of sesquiterpenes (for instance drimenol $3^{[4]}$ ).

Despite the success achieved in the head-to-tail[5] terpene cyclization with synthetic catalysts, a general synthetic

[a] Dr. Q. Zhang

Key Laboratory of Green Chemistry and Technology of Ministry of

Education, College of Chemistry, Sichuan University

29 Wangjiang Road, Chengdu 610064 (P.R. China)

[b] Prof. K. Tiefenbacher*

Department of Chemistry, University of Basel

Postfach 3350, Mattenstrasse 24a, 4002 Basel (Switzerland)

E-mail: konrad.tiefenbacher@unibas.ch

Department of Biosystems Science and Engineering, ETH Zurich

Mattenstrasse 26, 4058 Basel (Switzerland)

E-mail: tkonrad@ethz.ch

Supporting information and the ORCID identification number(s) for

the authors of this article can be found under:

http://dx.doi.org/ methodology to access the structurally more diverse terpene natural products produced by type I terpene cyclase enzymes is still lacking. One main challenge concerns the numerous reaction pathways of the reactive cationic intermediates involved in the socalled tail-to-head ${ }^{[5]}$ terpene cyclization. The allylic cation 4 (Scheme 1b), formed via the cleavage of the leaving group at the tail end of the molecule, is already able to undergo a variety of different cyclization reactions. The same holds true for subsequently formed cationic intermediates. Natural enzymes stabilize these reactive cationic intermediates via precisely positioned residues, employing stabilizing coulombic, cationdipole and cation- $\pi$ interactions. ${ }^{[2,6]}$ In solution, due to the lack of stabilization, the cationic intermediates are usually prematurely quenched by the cleaved leaving group and/or solvent molecules via elimination or substitution reactions, resulting mainly in acyclic or monocyclic structures. ${ }^{[7]}$ The Shenvi group tried to circumvent this issue by employing a modified epoxide-containing substrate capable of covalently linking the leaving group to the substrate after activation. ${ }^{[5]}$ As a result, after activation with stoichiometric amounts of aluminum Lewis acids, the free propagation of the positive charge enabled a non-stop ${ }^{[8]}$ cyclization cascade, delivering the strained sesquiterpene natural product funebrene as the main product. ${ }^{[5]}$ Although this result certainly constitutes a breakthrough in tail-to-head terpene cyclizations in solution, several challenges remain: (1) The use of readily available farnesol instead of a heavily modified substrate would streamline access to sesquiterpenes. (2) A catalytic cyclization reaction is desirable.

Recently, supramolecular structures emerged as a promising tool to reproduce the tail-to-head terpene cyclization. ${ }^{[9]}$ Similar to natural enzymes, guest molecules bind inside the cavity of these structures. In several systems, the driving force for the guest encapsulation is provided by the cation- $\pi$ stabilization. ${ }^{[10]}$ These properties render supramolecular structures potential enzyme mimetics. In the last decades, several examples of catalysis inside supramolecular containers have been reported. ${ }^{[10-11]}$ Among them, a tetrahedral supramolecular cage based on metalligand interaction, reported by the Raymond group, ${ }^{[12]}$ represents one of the most intensively investigated systems. Notably, a Prins-cyclization reaction using a monoterpene-like substrate was achieved by utilizing the metal-ligand cage as the catalyst. ${ }^{[13]}$

Our group ${ }^{[9,14]}$ and other groups ${ }^{[15]}$ applied the hexameric resorcinarene capsule I (Figure 1), originally reported by the Atwood group, ${ }^{[16]}$ as supramolecular catalyst. Driven by the formation of multiple intermolecular hydrogen bonds, capsule I self-assembles from six resorcinarene subunits 7 and eight water 
farnesyl pyrophosphate (1)<smiles>CC(C)=CCCC(C)=CCCC(C)=CCOP</smiles>

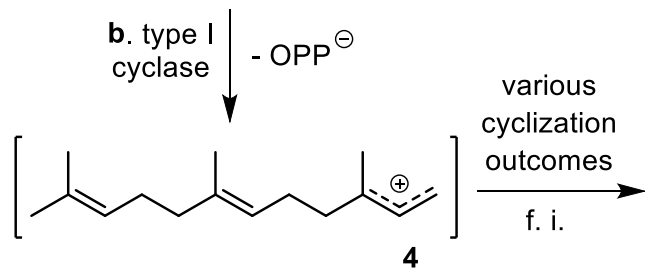

4

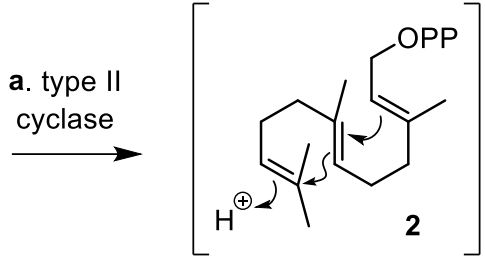<smiles>CC1=CCC2C(C)(CCC(CO)C2(C)C)C1</smiles>

f. i. drimenol (3)<smiles>C=C(CC=C(C)C)C1CC=C(C)CC1</smiles>

bisabolene (5)

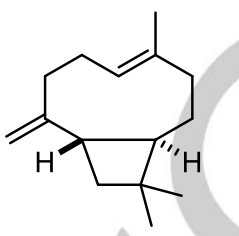

$(E)-\beta$-caryophyllene
(6)

\section{Results and Discussion}

At the outset of our investigation, the cyclization reaction of the commercially available (2E,6E)-farnesol (FOH, see Table 1 for structure) was tested under the optimal conditions established for monoterpene cyclization (10 mol\% I, $3 \mathrm{~mol} \% \mathrm{HCl}$ ). Complete conversion of the substrate was reached after $4 \mathrm{~d}$ as indicated by GC (SI-Figure 1). Based on ${ }^{1} \mathrm{H}$ and ${ }^{13} \mathrm{C}$ NMR comparison, supported by GC-MS database analysis, the major cyclization products were identified to be $\alpha$-cedrene $(\mathbf{A})$, $\delta$-selinene (B), 2 epi-a-cedrene (C), $\varepsilon$-patchoulene (D) and 10-epi-zonarene (E) (Table 1). ${ }^{[9 c]}$ The cyclization products were obtained in racemic form, since capsule I is assembled from achiral building blocks.

The cyclization behavior of $(2 E, 6 E)-\mathrm{FOH}$ has already been intensively investigated using regular Lewis or Brønsted acids. In these literature experiments, bisabolene (5, Scheme $1 \mathrm{~b})$ was formed as the dominant species. ${ }^{[7 a, 7 b]}$ Polycyclic products were only obtained in low yields, and as complex mixtures when the reprotonation of the monocyclic intermediate was forced under harsher acidic conditions. ${ }^{[19]}$ In the present study, the formation of polycyclic products was already observed during the initial reaction phase. Additionally, the product distribution only changed insignificantly as the reaction proceeded. These observations indicated that the capsule-catalyzed polycyclization likely did not follow a reprotonation mechanism. This, in turn, could indicate a better stabilization of the cationic intermediates involved in the cyclization cascade within the cavity of the supramolecular catalyst. To learn more about the prerequisite for the cyclization reaction, a series of control experiments was performed (SIchapter 5). When capsule I was omitted, no cyclization reaction could be detected under otherwise identical conditions. The same was true when capsule I was blocked with an inhibitor $\left(n \mathrm{Bu}_{4} \mathrm{NBr}\right)$. Replacing I with a closely related hexameric capsule unable to stabilize ion pairs ${ }^{[20]}$ also failed to affect any cyclization reaction.

Figure 1. Structure of the hexameric resorcinarene capsule. 
Altogether, these experiments strongly indicated that the cyclization reaction occurred inside the supramolecular assembly I, and that the formation of polycyclic products likely stemmed from the free propagation of the positive charge in the intermediates due to the cation- $\Pi$ stabilization within capsule $\mathbf{I}$.

Table 1. Cyclization reaction results of selected acyclic farnesyl substrates. Unless otherwise stated, the cyclization reactions were performed in $\mathrm{CHCl}_{3}$ with a substrate concentration of $33.3 \mathrm{mM}$ using $10 \mathrm{~mol} \% \mathrm{I}$ and $3 \mathrm{~mol} \% \mathrm{HCl}$ as the catalysts. $n$ Decane was used as the internal standard to quantify the GCyields. Given are yields corrected by response factors. a: Cyclization reaction was performed with $10 \mathrm{~mol} \% \mathrm{HCl}$ under otherwise identical conditions.

\begin{tabular}{ccccccc}
\hline Entry & Substrate & A & B & C & D & E \\
\hline 1 & $(2 E, 6 E)-$ FOAc & $6 \%$ & $8 \%$ & $5 \%$ & $6 \%$ & $12 \%$ \\
2 & $(2 Z, 6 E)-$ FOAc & $7 \%$ & $0 \%$ & $7 \%$ & $7 \%$ & $11 \%$ \\
3 & $(2 Z, 6 Z)-F O A c$ & $7 \%$ & $0 \%$ & $9 \%$ & $8 \%$ & $11 \%$ \\
4 & & $3 \%$ & $18 \%$ & $4 \%$ & $3 \%$ & $10 \%$ \\
$5^{\text {a }}$ & $(2 E, 6 Z)-$ FOAC & $3 \%$ & $22 \%$ & $3 \%$ & $1 \%$ & $4 \%$ \\
\hline
\end{tabular}
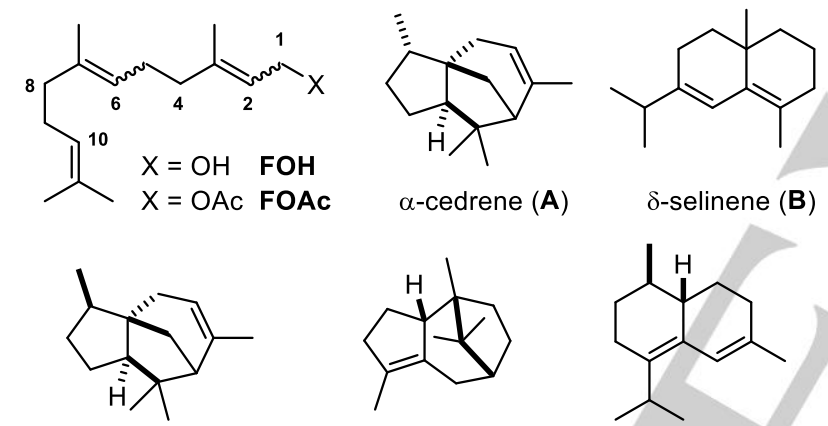

$\alpha$-cedrene (A)

$\delta$-selinene (B)

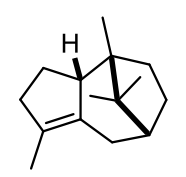

2-epi- $\alpha$-cedrene (C)

$\varepsilon$-patchoulene (D)

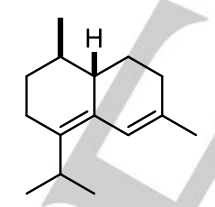

10-epi-zonarene (E)

The study on sesquiterpene cyclization was then expanded to all alkene isomers of farnesol (FOH) and farnesyl acetate (FOAc) as well as related substrates (Scheme $2 b$, SI-Figure 2-10). The product distribution of the cyclization reaction was greatly affected by the double bond geometry of the substrate. The reaction of $(2 E, 6 Z)$-FOAc yielded mainly $\delta$-selinene $(18 \%)$ in relatively good selectivity (Table 1 , entry 4 and SI-Figure 8$)$. The selectivity for $\delta$ selinene was greatly diminished in the reaction of $(2 E, 6 E)$-FOAc (Table 1 , entry 1 and SI-Figure 2). Since $\delta$-selinene is formed via an initial 1,10-ring closure, it seems likely that the Z-geometry of the internal $\mathrm{C} 6-\mathrm{C} 7$ double bond favors the required substrate conformations (Scheme 2c). Interestingly, $\delta$-selinene was absent in the product mixtures obtained from $(2 Z, 6 E)$-FOAc and $(2 Z, 6 Z)$ FOAC (Table 1, entries 2-3 and SI-Figure 4/6), indicating that the alternative 1,6-cyclization pathway was dominating in these two cases (Scheme 2a). The cyclization of bisabolyl acetate (9) delivered similar product profiles as the (2Z)-substrates (SI-Figure 11). This observation supports our conclusion that a 1,6-ring closure dominates in the case of the (2Z)-substrates. The cyclization reactions of the nerolidyl acetates $\mathbf{1 0}$ and $\mathbf{1 1}$ (Scheme 2b) proceeded likely via both cyclization modes, therefore delivering complex product mixtures. Compared to its $(E)$-isomer (SI-Figure 9), (6Z)-nerolidyl acetate (SI-Figure 10) produced a more pronounced formation of $\delta$-selinene. This is in line with our previous observation made with the farnesyl substrates.

Influence of reaction parameters. The 1,10-cyclization pathway was investigated in more detail. It was found that the cyclization outcome from (2E,6Z)-FOAc was influenced by the reaction parameters. The ratio between $\delta$-selinene $(\mathbf{B})$ and 10 epi-zonarene (E) was increased with higher amount of $\mathrm{HCl}$ (up to $10 \mathrm{~mol} \%$ ) as the co-catalyst (Table 1, entry 5, Scheme 3b, SITable 1). However, a further increase in the $\mathrm{HCl}$-loading resulted in diminished yields (SI-Figure 13). In the proposed mechanism ${ }^{[21]}$ for the formation of $\delta$-selinene (Scheme $2 \mathrm{c}$ ), protonation on the C6-C7 double bond of the cyclodecadiene intermediate 16 is required to initiate the 2,7-ring closure. This protonation step may be facilitated under more acidic conditions, delivering $\delta$-selinene as the only major product in useful yields (22\%). These optimized conditions lead to a more selective cyclization outcome than observed with the natural $\delta$-selinene cyclase, ${ }^{[21]}$ as can be seen by a visual comparison of the two GC spectra (Scheme 3b vs. 3c).

In contrast, elevated temperatures shifted the selectivity slightly towards 10-epi-zonarene in the reaction of $(2 E, 6 Z)$-FOAc, while not changing the general reaction profile (SI-Figure 14). Although, mechanistically, 10-epi-zonarene may arise from both cyclization modes, ${ }^{[22]}$ we excluded a switch towards the 1,6-cyclization pathway at higher temperature due to the unchanged reaction profile. In the case of the 1,10-cyclization pathway, the $(2 E)$ double bond in the 10-membered ring intermediate 12 (highlighted in blue in Scheme 2) has to isomerize to its $Z$ configuration (highlighted in red in Scheme 2) prior to the final 1,6ring closure. This conformational change is likely more facile at higher temperature, resulting in a more pronounced formation of 10-epi-zonarene (SI-Figure 14). We next sought to selectively form 10-epi-zonarene. To this end, the cyclization reaction of $(2 E, 6 E)$-FOAc was further examined, since it already favored 10 epi-zonarene under the standard reaction conditions (Table 1, entry 1 and SI-Figure 2). Nevertheless, all attempts to improve the yield of $\mathbf{E}$ by increasing the reaction temperature and/or reducing the $\mathrm{HCl}$-content failed (SI-Figure 12). The failure was likely due to two reasons: (1) The 1,10-macrocyclization is impeded due to the presence of the E-configured internal double bond. As a result, the 1,6-cyclization pathway is competitive. (2) In the 1,10cyclization, $\delta$-selinene seems to be the preferred product. Consequently, its formation is very hard to suppress.

Application in total synthesis. We then translated the selective cyclization of (2E,6Z)-FOAc into a synthetic application. Starting from the commercially available monoterpene nerol (18), the isomerically pure cyclization precursor (2E,6Z)-FOAc was readily synthesized on a gram scale in a six step-sequence ${ }^{[23]}$ (Scheme 3a). After the completion of the cyclization reaction, the resorcinarene was removed by an initial column chromatography. Subsequent purification of the resulting crude product on $\mathrm{AgNO}_{3-}$ impregnated silica gel enabled the isolation of $\delta$-selinene as a pure compound (SI-chapter 4). To the best of our knowledge, this 
synthetic sequence also constitutes the first total synthesis of the sesquiterpene natural product $\delta$-selinene.
In our initial communication, we reported the cyclization of the monocyclic substrate cycloFOAc under the standard reaction

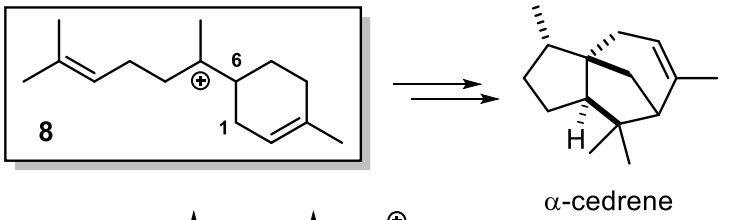

(A)

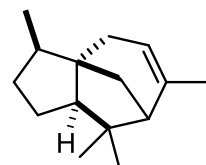

2-epi- $\alpha$-cedrene

(C)

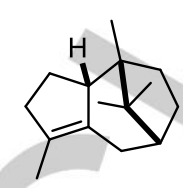

$\varepsilon$-patchoulene

(D)

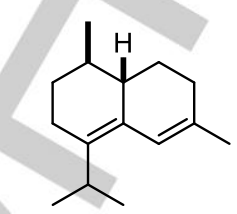

10-epi-zonarene

(E)

b

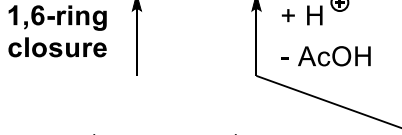<smiles>[X]CC=C(C)CCC=C(C)CCC=C(C)C</smiles>

$\mathrm{X}=\mathrm{OH}$ farnesol (FOH)

$X=O A c$ farnesyl acetate (FOAC)<smiles>CC(C)=CCCC(C)(C)C1CC=C(C)CC1</smiles><smiles>C=CC(C)(CC/C=C(/C)CCC=C(C)C)OC(=O)O</smiles><smiles>C=CC(C)(CCC=C(C)CCC=C(C)C)OC(C)=O</smiles>

Bisabolyl acetate (9)

(Z)-nerolidyl acetate (11) \begin{tabular}{c|c}
$\begin{array}{c}\text { 1,10-ring } \\
\text { closure }\end{array}$ & $\begin{array}{c}\text { in the case of } \\
(2 E) \text {-FOH/FOAC }\end{array}$
\end{tabular}

C

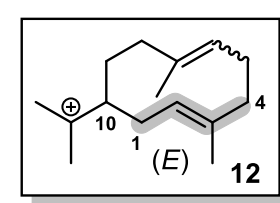

$1,2-$ hydride

shift<smiles>CCC=C1CC=C(C)C(C(C)C)CC1</smiles>

15<smiles>CCCC=C1CCC(C=C(C)C)C(C(C)C)CC1</smiles>

13

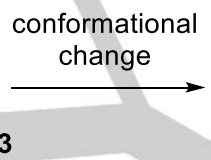

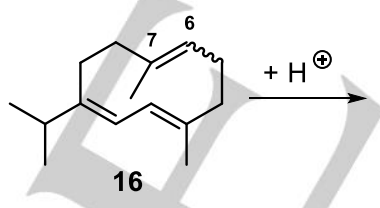

16<smiles>CC1=CC2(C=C(C(C)C)CCC2)CC1</smiles>

17

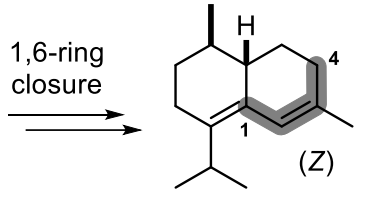

10-epi-zonarene

(E)<smiles>C=CC(C)C1=C([AlH2])C2=C(C)CCCC2(C)CC1</smiles>

Scheme 2. Proposed mechanism for the cyclization reaction of sesquiterpene substrates (b) catalyzed by capsule I. (a) The cyclization reactions of the (2Z)-substrates occur via the 1,6-pathway. (c) The alternative 1,10-cyclization mode is feasible with substrates featuring the $(2 E)$-alkene moiety. a

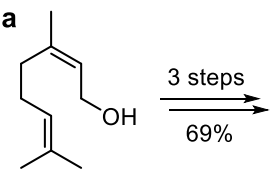

nerol (18)
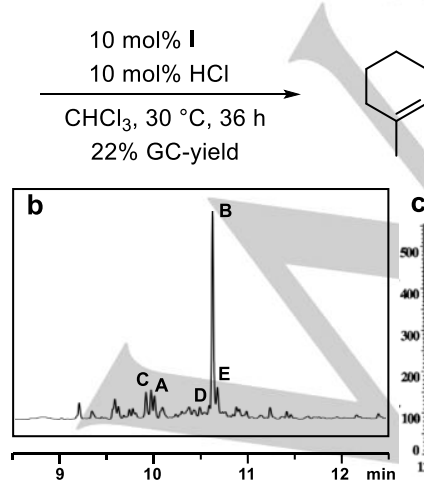

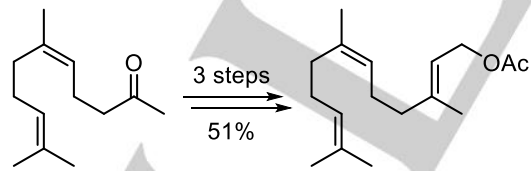

(2E,6Z)-FOAC neryl acetone (19)
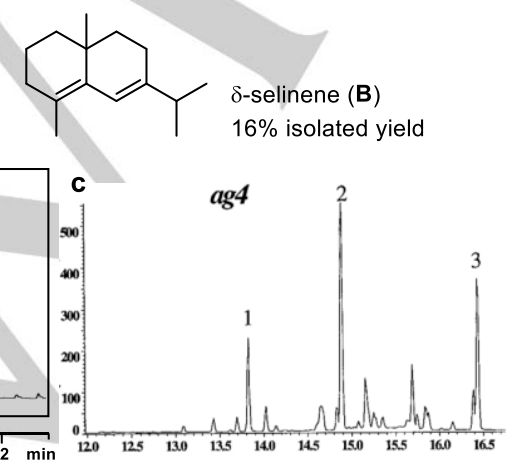

Scheme 3. Total synthesis of $\delta$-selinene with the capsulecatalyzed cyclization reaction as the key step (a). GC-traces of the cyclization reaction of $(2 E, 6 Z)$-FOAc under optimized conditions (b). The intensities of the peaks in the gas chromatography traces are normalized to an internal standard (for full spectra, see SI-Figure 13). (c). The total ion chromatogram of the cyclization reaction of farnesyl pyrophosphate with $\delta$ selinene-synthase. ${ }^{[21]} \delta$-Selinene is labelled as compound 2 in Scheme 3c. Compound 1 and 3 are Guaia-6,9-diene and Germacrene, respectively (for the structures of 1 and 3 , see SIFigure 17). Scheme $3 c$ is reproduced with the permission of Journal of Biological Chemistry.

conditions $^{[9 c]}$ (Scheme $\left.4 \mathrm{a}\right)$ to deliver the tricyclic sesquiterpene natural product isolongifolene $(\mathbf{F}) .^{[24]}$ The access to $\delta$-selinene reported herein represents the first total synthesis of a sesquiterpene natural product that is based on the cyclization of a linear terpene precursor inside a supramolecular container. 
Kinetic investigations. In comparison with the monoterpene cyclizations, ${ }^{[9 b]}$ we observed a much slower conversion of sesquiterpenes inside capsule I. To elucidate the cause of this observation, we investigated the kinetics of the cyclization of sesquiterpenes by using the initial rate method (Figure 2, SIchapter 6$)$. The cyclization of $(2 E, 6 Z)$-FOAc was selected as the model reaction, since it displayed the highest product selectivity. Under the standard reaction conditions (10 mol\% I and $3 \mathrm{~mol} \%$ $\mathrm{HCl}$ ), the reaction rate of the sesquiterpene cyclization was measured to be first-order in the substrate concentration (Figure 2a). Activation parameters were obtained by performing the cyclization reaction at three different temperatures $\left(30^{\circ} \mathrm{C}, 40^{\circ} \mathrm{C}\right.$ and $50^{\circ} \mathrm{C}$ ). The values for $\Delta H^{\neq}, \Delta S^{\neq}, \Delta G^{\neq}$were determined to be $31.0 \pm 0.6 \mathrm{kcal} \cdot \mathrm{mol}^{-1}, 18.4 \pm 2.1 \mathrm{cal} \cdot \mathrm{mol}^{-1} \cdot \mathrm{K}^{-1}$ and $25.4 \pm 0.1 \mathrm{kcal} \cdot \mathrm{mol}$ ${ }^{1}$, respectively (Table 2 , entry 31 ), indicating an entropically favored rate-limiting step. Subsequently, all other farnesyl isomers, as well as the two cyclofarnesyl substrates were investigated in a similar fashion (Table 2, SI-chapter 6). a<smiles>CC(=O)CCC1=C(C)CCCC1(C)C</smiles>

Dihydro- $\beta$-ionone $(20)$

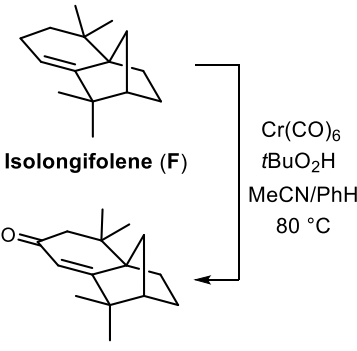

Isolongifolenone (21) [13\% isolated yield from 20$]$

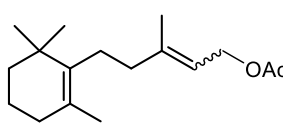

cycloFOAc $(E / Z=6 / 1)$

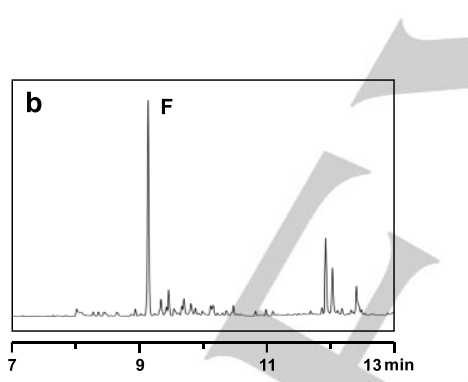

Scheme 4. Total synthesis of isolongifolenone with the capsulecatalyzed cyclization reaction as the key step (a). GC-trace of the cyclization reaction of cycloFOAc (b).

Rate-determining step. Similar to the reactions of monoterpenes (entries 39 and 40), , ${ }^{[9 b]}$ the cyclization of $(2 E, 6 Z)$ FOAC also featured a positive entropy of activation (Table 2, with the exception of entry 32 where a different solvent was utilized, see discussion below). In the case of monoterpene cyclizations, the positive entropy of activation was attributed to the cleavage of the activated leaving group in the rate-determining step of the catalytic cycle. ${ }^{[9 b]}$ Therefore, a similar rate-limiting step might be operational in the sesquiterpene cyclization. However, the rate constant determined for (2E,6Z)-FOAc (Table 2, entry 1-3) was approximately one order of magnitude smaller than those of monoterpene cyclizations (Table 2, entries 25-30). The same was true for other alkene isomers of farnesyl acetate and also the monocyclic substrates (Table 2, entries 7-21, for details see SIchapter 6). We considered two initial hypotheses to rationalize the attenuation of the rate constants in the sesquiterpene cyclizations: (1) A different cyclization mode. In the concerted cyclization mechanism, the cyclization is accompanied by the rate-limiting cleavage of the leaving group (f. i. the cyclization of neryl acetate, Table 2, entries 28-30 and 40). ${ }^{\left[{ }^{[b]}\right]}$ Consequently, the overall reaction rate is also affected by the ease of the ring closure. In monoterpene cyclizations, the initial cyclization is limited to the 1,6-ring closure. In the case of sesquiterpenes, however, the 1,10-cyclization mode is also feasible. The formation of a more strained 10-membered ring could, in principle, pose a higher energy barrier than the more facile 1,6-ring closure, resulting in a reduced rate constant. However, also the (2Z)sesquiterpene substrates that reacted mainly via the 1,6-ring closure displayed smaller rate constants (Table 2, entries 10-15). (2) Sesquiterpene substrates may display an alternative ratedetermining step. Instead of the cleavage of the leaving group, another rate-determining step may be operational in the cyclization of sesquiterpene.

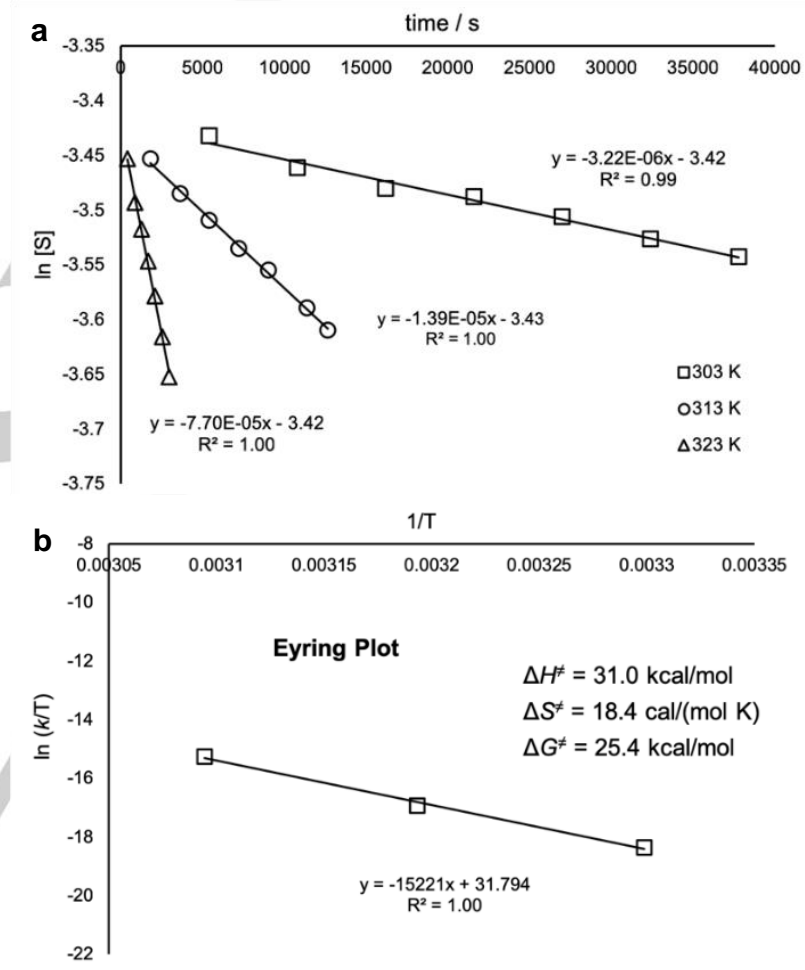

Figure 2. Kinetic investigation of the cyclization of (2E,6Z)-FOAc. (a) The reaction rate was determined to be first-order in the substrate concentration. (b) Activation parameters obtained indicated that the rate-determining step of the cyclization reaction was entropically favorable.

To learn more about the rate-limiting step, the sesquiterpene substrate ext-GOAc (22, Scheme 5a) which is unable to undergo a 1,10-ring closure was synthesized and investigated in detail (SIchapter 7). Under the standard cyclization conditions, compound 22 was converted to a major species in relatively good selectivity as indicated by gas chromatography analysis (SI-Figure 27). Subsequent NMR analysis (SI-Figure 28 and SI-chapter 10) revealed that the cyclization behavior of ext-GOAc resembled that of geranyl acetate (GOAc), yielding the extended analogue (24) of a-terpinene (23) as the dominant cyclization product (Scheme 5a). In accordance with the other sesquiterpene substrates, the extended analogue of geranyl acetate also 
exhibited a much smaller rate constant (Table 2, entries 22-24) than the monoterpene substrates. This result indicated that the energetically more demanding 1,10-cyclization mode was most likely not the cause for the slower conversion of sesquiterpenes. Additionally, we decided to investigate the secondary kinetic isotope effect (KIE). If the cleavage of the leaving group is the slowest step, as observed for the monoterpene cyclization, a normal secondary KIE should be observed. However, no secondary KIE was observed for the sesquiterpene substrate 22 under the same reaction conditions as employed for monoterpene cyclizations. (Scheme $5 \mathrm{~b}$ ). Taken together, these experiments provided strong evidence that the cleavage of the leaving group is not the rate-limiting step in the sesquiterpene cyclization.

Table 2. Summary of activation parameters of the sesquiterpene substrates. The cyclization reactions were performed in $\mathrm{CHCl}_{3}$ with a substrate concentration of $33.3 \mathrm{mM}$ using $10 \mathrm{~mol} \% \mathrm{I}$ and $3 \mathrm{~mol} \% \mathrm{HCl}$ as the catalysts. The Gibbs free energies at $303 \mathrm{~K}$ are given. The values determined with monoterpene substrates ${ }^{[9 b]}$ are compared at the bottom of the table. ${ }^{a}$ 1,1,2,2-tetrachloroethane was used the solvent instead of $\mathrm{CHCl}_{3}$ (highlighted with a gray box).

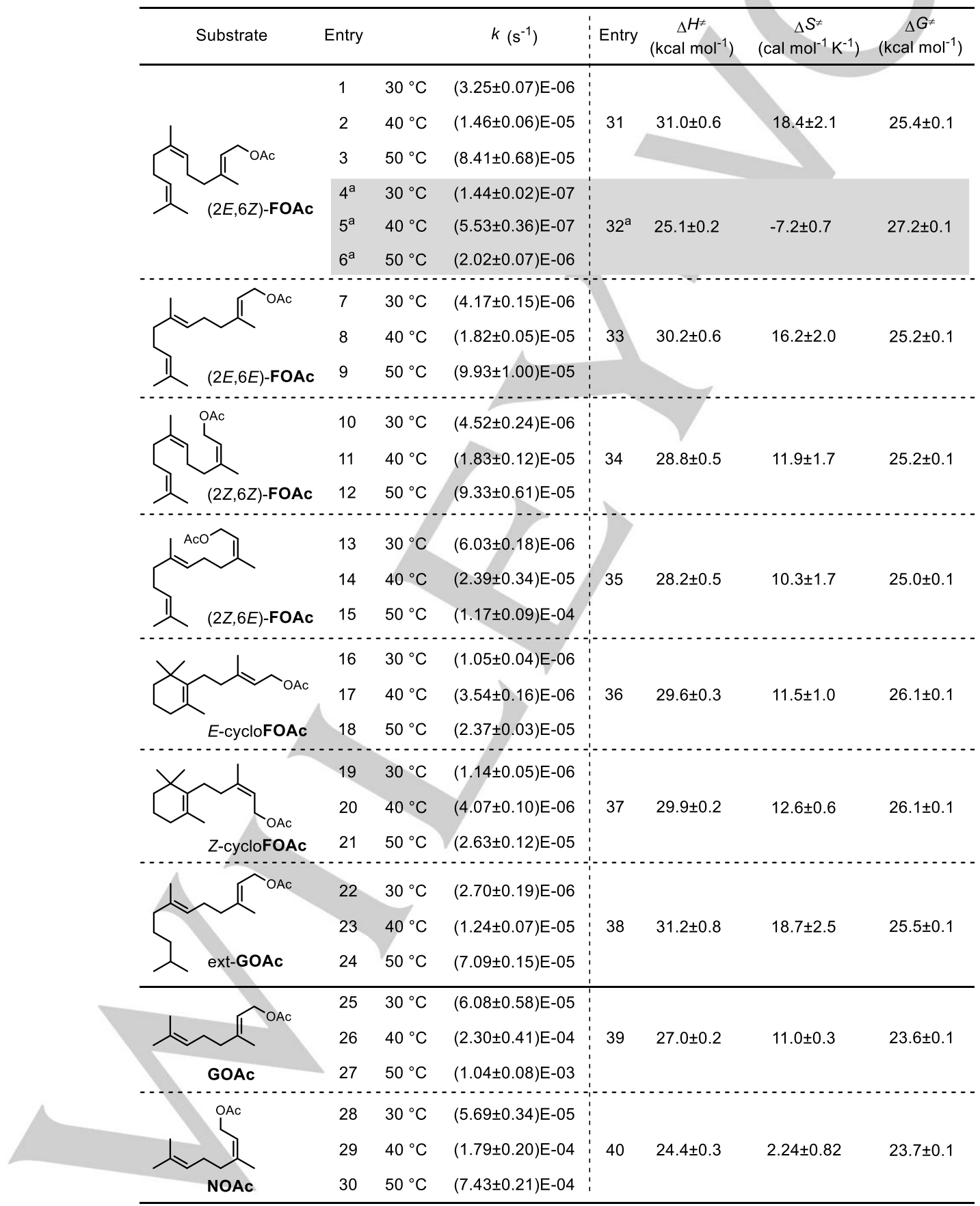


Scheme 5. Detailed comparison of geranyl acetate (GOAc) and its sesquiterpene analogue ext-GOAc concerning the cyclization behavior (a), and the kinetic isotope effect observed (b).

a Similar cyclization behaviour

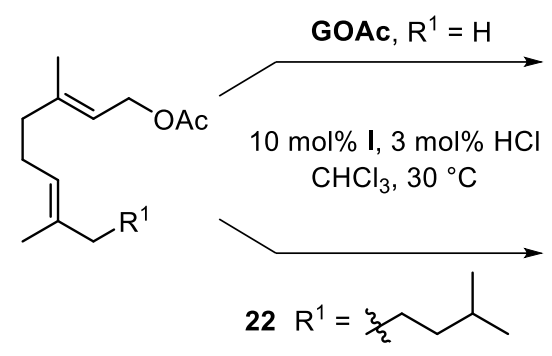

b Different kinetic isotope effect<smiles>[R]CC(C)=CCCC(C)=CC([R])([R])OC(C)=O</smiles>

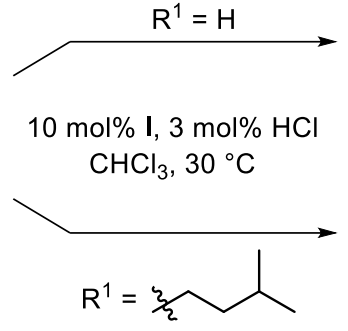

Normal secondary
kinetic isotope effect
$k_{H / D}=1.22 \pm 0.04$

No secondary kinetic isotope effect $k_{\mathrm{H} / \mathrm{D}}=1.00 \pm 0.04$

The positive entropy of activation determined for the sesquiterpene substrates is indicative of a more disordered transition state in the rate-determining step as compared to its ground state. After having excluded the cleavage of leaving group as the rate-determining step, the encapsulation of substrate remained the most plausible reaction step with a positive entropy of activation. $\mathrm{A}^{1} \mathrm{H}$ NMR experiment (SI-Figure 33 ) suggested that the resorcinarene capsule may accommodate approximately eight chloroform molecules (each with a molecular volume of approx. $72 \AA^{3}$. For details, see SI-Table 12) in its cavity $\left(1422 \AA^{3}\right.$ ). According to molecular modelling, the encapsulation of a sesquiterpene substrate $\left(292 \AA^{3}\right)$ would displace approx. four chloroform molecules from the cavity of capsule I (SI-Figure 35). The resulting increase in entropy (non-encapsulated molecules: $\Delta=+3$, SI-Table 12) may explain the higher entropy of activation than that observed in the case of monoterpene cyclization. For monoterpenes, the entropic gain was attributed to the liberation of the leaving group (increase in number of molecules: $\Delta=+1$ ) When the cyclization reaction of $(2 E, 6 Z)$-FOAc was performed in a bulkier solvent (1,1,2,2-tetrachloroethane, $\left.108 \AA^{3}\right)$, the rate constant further decreased (Table 2, entries 4-6), probably due to the diminished entropic gain (non-encapsulated molecules: $\Delta=$ approx. +2). Even a negative value was determined for the entropy of activation $\left(\Delta S^{\neq}=-7.2 \pm 0.7 \mathrm{cal} \cdot \mathrm{mol}^{-1} \cdot \mathrm{K}^{-1}\right.$, Table 2 , entry 32). Guest exchange in I was proposed to occur via a pentameric capsule species featuring a temporary portal created by the dissociation of one resorcinarene subunit. ${ }^{[25]}$ The incoming substrate may experience a higher conformational restriction at the portal when displacing the bulkier solvent molecules previously encapsulated by capsule I. In turn, this may compensate the entropy gained by the liberation of solvent

molecules and result in a greatly reduced entropy of activation. These results, together with the observed absence of a secondary kinetic isotope effect, indicate that the substrate uptake is indeed rate-limiting for sesquiterpene cyclizations.

\section{Summary}

We herein report our detailed studies on the tail-to-head sesquiterpene cyclizations catalyzed by the resorcinarene capsule. The cyclization reactions were systematically investigated by varying the double bond geometry and the leaving group of the substrates. The most selective conversion was displayed by $(2 E, 6 Z)$-farnesyl acetate, yielding $\delta$-selinene and 10 epi-zonarene as the two major products. The selectivity for $\delta$ selinene could be further improved by increasing the amount of the cocatalyst $\mathrm{HCl}$. This resulted in a higher selectivity for the formation of $\delta$-selinene than the reaction catalyzed by the corresponding natural cyclase. By utilizing the selective transformation of $(2 E, 6 Z)$-FOAc as the key step, the first total synthesis of the sesquiterpene natural product $\delta$-selinene was achieved. This represents the first total synthesis of a sesquiterpene natural product that is based on the cyclization of a linear terpene precursor inside a supramolecular catalyst. Detailed kinetic investigations of seven substrates were performed to elucidate the reaction mechanism. In the cyclization of monoterpenes, the reaction rate was determined by the cleavage of the leaving group. For sesquiterpene substrates, significantly attenuated rate constants, higher entropies of activation, and the absence of a secondary kinetic isotope effect were observed. These results strongly indicate that the encapsulation of substrate is the rate-limiting step for sesquiterpene cyclizations.

\section{Acknowledgements}

This work was supported by funding from the European Research Council Horizon 2020 Programme [ERC Starting Grant 714620TERPENECAT], the Swiss National Science Foundation as part of the NCCR Molecular Systems Engineering and the Bayerische Akademie der Wissenschaften (Junges Kolleg)

Keywords: Supramolecular catalysis, terpene cyclization, enzyme-mimicking, resorcinarene capsule, host-guest systems.

[1] (a) T. J. Maimone, P. S. Baran, Nat. Chem. Biol. 2007, 3, 396; (b) D. Urabe, T. Asaba, M. Inoue, Chem. Rev. 2015, 115, 9207-9231.

[2] D. W. Christianson, Chem. Rev. 2017, 117, 11570-11648.

[3] (a) R. A. Yoder, J. N. Johnston, Chem. Rev. 2005, 105, 4730-4756; (b) C. N. Ungarean, E. H. Southgate, D. Sarlah, Org. Biomol. Chem. 2016, 14, 5454-5467; (c) S. A. Snyder, D. S. Treitler, A. P. Brucks, Aldrichim Acta 2011, 44, 27-40; (d) W.-j. Chung, C. D. Vanderwal, Angew. Chem. Int. Ed. 2016, 55, 4396-4434; (e) R. C. Samanta, H. Yamamoto, J. Am. Chem. Soc. 2017, 139, 1460-1463; (f) A. M. Arnold, A. Pöthig, M. Drees, T. Gulder, J. Am. Chem. Soc. 2018, 140, 4344-4353; (g) J. Bock, C. G. Daniliuc, U. Hennecke, Org. Lett. 2019, 21, 1704-1707; (h) Z. Tao, K. A. Robb, K. Zhao, S. E. Denmark, J. Am. Chem. Soc. 2018, 140, 3569-3573. 
[4] D. V. Banthorpe, J. T. Brown, G. S. Morris, Phytochemistry 1992, 31 3391-3395.

[5] S. V. Pronin, R. A. Shenvi, Nat. Chem. 2012, 4, 915.

[6] (a) C. M. Paschall, J. Hasserodt, T. Jones, R. A. Lerner, K. D. Janda, D. W. Christianson, Angew. Chem. Int. Ed. 1999, 38, 1743-1747; (b) J. C. Ma, D. A. Dougherty, Chem. Rev. 1997, 97, 1303-1324.

[7] (a) C. D. Gutsche, J. R. Maycock, C. T. Chang, Tetrahedron 1968, 24 , 859-876; (b) S. Sakane, J. Fujiwara, K. Maruoka, H. Yamamoto, J. Am. Chem. Soc. 1983, 105, 6154-6155; (c) A. L. P. de Meireles, M. d. S Costa, K. A. da Silva Rocha, E. V. Gusevskaya, Appl. Catal., A 2015 502, 271-275

[8] A. Eschenmoser, L. Ruzicka, O. Jeger, D. Arigoni, Helv. Chim. Acta 1955 38, 1890-1904.

[9] (a) Q. Zhang, K. Tiefenbacher, Nat. Chem. 2015, 7, 197-202; (b) Q. Zhang, L. Catti, J. Pleiss, K. Tiefenbacher, J. Am. Chem. Soc. 2017, 139 11482-11492; (c) Q. Zhang, J. Rinkel, B. Goldfuss, J. S. Dickschat, K. Tiefenbacher, Nat. Catal. 2018, 1, 609-615.

[10] L. Catti, Q. Zhang, K. Tiefenbacher, Synthesis 2016, 48, 313-328.

[11] (a) M. Yoshizawa, J. K. Klosterman, M. Fujita, Angew. Chem. Int. Ed. 2009, 48, 3418-3438; (b) J. Meeuwissen, J. N. H. Reek, Nat. Chem. 2010 2, 615; (c) L. Marchetti, M. Levine, ACS Catalysis 2011, 1, 1090-1118; (d) M. J. Wiester, P. A. Ulmann, C. A. Mirkin, Angew. Chem. Int. Ed. 2011 50, 114-137; (e) M. Raynal, P. Ballester, A. Vidal-Ferran, P. W. N. M. van Leeuwen, Chem. Soc. Rev. 2014, 43, 1734-1787; (f) C. J. Brown, F. D. Toste, R. G. Bergman, K. N. Raymond, Chem. Rev. 2015, 115, 30123035; (g) S. Zarra, D. M. Wood, D. A. Roberts, J. R. Nitschke, Chem Soc. Rev. 2015, 44, 419-432; (h) L. Catti, Q. Zhang, K. Tiefenbacher, Chem. Eur. J. 2016, 22, 9060-9066; (i) Q. Zhang, L. Catti, K Tiefenbacher, Acc. Chem. Res. 2018, 51, 2107-2114; (j) Y. Zhu, J. Rebek Jr, Y. Yu, Chem. Commun. 2019; (k) W. Cullen, M. C. Misuraca C. A. Hunter, N. H. Williams, M. D. Ward, Nat. Chem. 2016, 8, 231; (I) M. D. Levin, D. M. Kaphan, C. M. Hong, R. G. Bergman, K. N. Raymond, F. D. Toste, J. Am. Chem. Soc. 2016, 138, 9682-9693; (m) A. C. H. Jans, A. Gómez-Suárez, S. P. Nolan, J. N. H. Reek, Chem. Eur. J. 2016, 22 , 14836-14839; (n) P. F. Kuijpers, M. Otte, M. Dürr, I. Ivanović-Burmazović, J. N. H. Reek, B. de Bruin, ACS Catalysis 2016, 6, 3106-3112; (o) Q.-Q. Wang, S. Gonell, S. H. A. M. Leenders, M. Dürr, I. Ivanović-Burmazović, J. N. H. Reek, Nat. Chem. 2016, 8, 225; (p) Y. Ueda, H. Ito, D. Fujita, M. Fujita, J. Am. Chem. Soc. 2017, 139, 6090-6093; (q) C. Gaeta, C. Talotta, M. De Rosa, P. La Manna, A. Soriente, P. Neri, 2019, 25, 4899-4913.

[12] D. L. Caulder, R. E. Powers, T. N. Parac, K. N. Raymond, Angew. Chem. Int. Ed. 1998, 37, 1840-1843.

[13] W. M. Hart-Cooper, K. N. Clary, F. D. Toste, R. G. Bergman, K. N. Raymond, J. Am. Chem. Soc. 2012, 134, 17873-17876.

[14] (a) Q. Zhang, K. Tiefenbacher, J. Am. Chem. Soc. 2013, 135, 1621316219; (b) L. Catti, K. Tiefenbacher, Chem. Commun. 2015, 51, 892-894; (c) T. M. Bräuer, Q. Zhang, K. Tiefenbacher, Angew. Chem. Int. Ed. 2016 , 55, 7698-7701; (d) L. Catti, A. Pöthig, K. Tiefenbacher, Adv. Synth. Catal. 2017, 359, 1331-1338; (e) T. M. Bräuer, Q. Zhang, K. Tiefenbacher, J. Am. Chem. Soc. 2017, 139, 17500-17507; (f) L. Catti, K. Tiefenbacher, Angew. Chem. Int. Ed. 2018, 57, 14589-14592; (g) J. M. Köster, K. Tiefenbacher, ChemCatChem 2018, 10, 2941-2944; (h) J. M. Köster, D. Häussinger, K. Tiefenbacher, Front. Chem. 2019, 6.

[15] (a) G. Bianchini, G. L. Sorella, N. Canever, A. Scarso, G. Strukul, Chem. Commun. 2013, 49, 5322-5324; (b) S. Giust, G. La Sorella, L. Sperni, F. Fabris, G. Strukul, A. Scarso, Asian J. Org. Chem. 2015, 4, 217-220; (c) G. La Sorella, L. Sperni, G. Strukul, A. Scarso, ChemCatChem 2015, 7, 291-296; (d) T. Caneva, L. Sperni, G. Strukul, A. Scarso, RSC Advances 2016, 6, 83505-83509; (e) G. La Sorella, L. Sperni, P. Ballester, G. Strukul, A. Scarso, Catal. Sci. Technol. 2016, 6, 6031-6036; (f) G. La Sorella, L. Sperni, G. Strukul, A. Scarso, Adv. Synth. Catal. 2016, 358, 3443-3449; (g) P. La Manna, M. De Rosa, C. Talotta, C. Gaeta, A Soriente, G. Floresta, A. Rescifina, P. Neri, Org. Chem. Front. 2018, 5, 827-837; (h) P. La Manna, C. Talotta, G. Floresta, M. De Rosa, A. Soriente, A. Rescifina, C. Gaeta, P. Neri, Angew. Chem. Int. Ed. 2018, 57, 5423-5428.
[16] (a) L. R. MacGillivray, J. L. Atwood, Nature 1997, 389, 469; (b) L. Avram, Y. Cohen, J. Rebek Jr, Chem. Commun. 2011, 47, 5368-5375.

[17] (a) L. Avram, Y. Cohen, J. Am. Chem. Soc. 2002, 124, 15148-15149; (b) T. Evan-Salem, I. Baruch, L. Avram, Y. Cohen, L. C. Palmer, J. Rebek, Proc. Natl. Acad. Sci. USA 2006, 103, 12296-12300.

[18] I. Horin, T. Adiri, Y. Zafrani, Y. Cohen, Org. Lett. 2018, 20, 3958-3961.

[19] (a) O. Yoshimoto, H. Yoshio, Chem. Lett. 1972, 1, 263-266; (b) N. H. Andersen, D. D. Syrdal, Tetrahedron Lett. 1972, 13, 2455-2458.

[20] Q. Zhang, L. Catti, V. R. I. Kaila, K. Tiefenbacher, Chem. Sci. 2017, 8, 1653-1657.

[21] C. L. Steele, J. Crock, J. Bohlmann, R. Croteau, J. Biol. Chem. 1998 273, 2078-2089.

[22] J. A. Faraldos, D. J. Miller, V. González, Z. Yoosuf-Aly, O. Cascón, A. Li, R. K. Allemann, J. Am. Chem. Soc. 2012, 134, 5900-5908.

[23] S. A. Snyder, D. S. Treitler, A. P. Brucks, J. Am. Chem. Soc. 2010, 132, 14303-14314.

[24] J. A. Klun, A. Zhang, S. Wang, J. F. Carroll, M. Debboun, J. Med Entomol. 2009, 46, 100-106.

[25] M. Yamanaka, A. Shivanyuk, J. Rebek, J. Am. Chem. Soc. 2004, 126, 2939-2943. 


\section{RESEARCH ARTICLE}

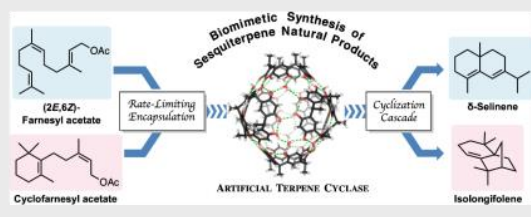

The resorcinarene capsule was utilized as a supramolecular catalyst for the tail-tohead sesquiterpene cyclization. The total synthesis of sesquiterpene natural products was achieved with the cyclization reaction inside the capsule as the key step. Detailed kinetic studies revealed a surprising switch of the rate-determining step in sesquiterpene cyclizations as compared to monoterpene cyclizations.
Qi Zhang, Konrad Tiefenbacher*

Page No. - Page No.

Sesquiterpene Cyclizations inside the Hexameric Resorcinarene Capsule: Total Synthesis of $\delta$-Selinene and Mechanistic Studies 